\title{
A unique appendiceal orifice: a striking foreign body in the cecum
}

\author{
Hamzeh Saraireha, Mohammad Bilal ${ }^{b}$, Karen Szauter ${ }^{\mathrm{b}}$ \\ University of Texas Medical Branch at Galveston, US
}

A 64-year-old female with a history of hypertension, obesity and hyperlipidemia presented to the Gastroenterology clinic with fatigue. Laboratory workup was consistent with iron-deficiency anemia, supported by low mean corpuscular volume and low ferritin. Esophagogastroduodenoscopy (EGD) and colonoscopy were scheduled. EGD revealed two sessile polyps in the body of the stomach and the biopsy was consistent with welldifferentiated grade 1 neuroendocrine tumor. Colonoscopy was performed and on intubation of the cecum a unique incidental foreign body was seen in the appendiceal orifice (Fig. 1). The foreign body was successfully removed with the use of a rat tooth forceps. The foreign body was identified to be a piece of a "spork" (Fig. 2), and patient had no recollection of its ingestion.

Ingestion of a foreign body in healthy adults is unusual and usually accidental. Risk factors for intentional foreign body ingestion include developmental delay, alcohol intoxication, incarceration and psychiatric illness [1]. Accidentally ingested foreign bodies usually go undetected and pass without any incidents. However, up to $20 \%$ require endoscopic removal [2]. Endoscopic removal of a foreign body is indicated if it is greater than $6 \mathrm{~cm}$ in length and $2.5 \mathrm{~cm}$ in diameter [3]. A foreign body in the appendiceal orifice or cecum may cause obstruction and could lead to subsequent acute appendicitis and perforation, resulting in significant morbidity and mortality.

Departments of a Internal Medicine (Hamzeh Saraireh); ${ }^{\mathrm{b}}$ Internal Medicine, Division of Gastroenterology and Hepatology (Mohammad Bilal, Karen Szauter), University of Texas Medical Branch at Galveston, Galveston, TX, USA

Conflict of Interest: None

Correspondence to: Hamzeh Saraireh, Departments of Internal Medicine, e-mail: hasarair@UTMB.EDU

Received 11 June 2017; accepted 18 June 2017; published online 2 August 2017

DOI: https://doi.org/10.20524/aog.2017.0184

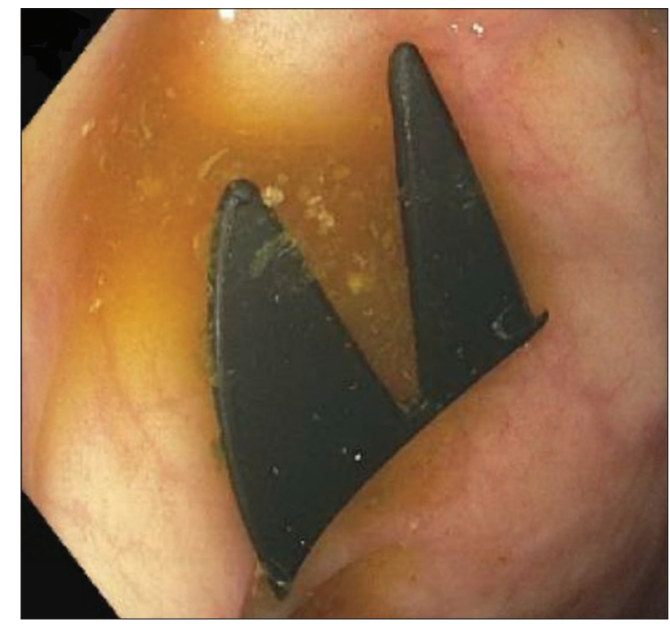

Figure $1 \mathrm{~A}$ unique incidental foreign body was seen in the appendiceal orifice

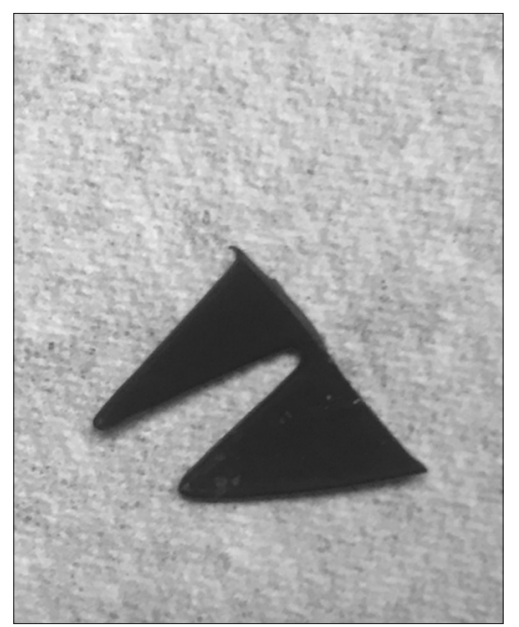

Figure 2 The foreign body was identified to be a piece of a "spork"

\section{References}

1. Hershman M, Shamah S, Mudireddy P, Glick M. Pointing towards colonoscopy: sharp foreign body removal via colonoscopy. Ann Gastroenterol 2017;30:254-256.

2. Müller KE, Arató A, Lakatos PL, Papp M, Veres G. Foreign body impaction in the sigmoid colon: a twenty euro bet. World $J$ Gastroenterol 2013;19:3892-3894.

3. Umar S, Moussaide G, Bilal M, Aoun E. Stomach with glasses: a striking foreign body. ACG Case Rep J 2017;4:e18. 